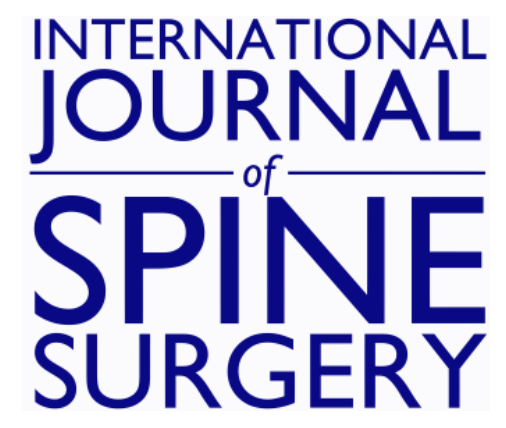

\title{
Remote Cerebellar Hemorrhage Complicating Unintended Durotomy in Lumbar Spine Surgery
}

Yizhar Floman, Michael A Millgram, Ely Ashkenazi and Nahshon Rand

Int J Spine Surg 2015, 9 ()

doi: https://doi.org/10.14444/2029

http://ijssurgery.com/content/9/29

This information is current as of April 26, 2023.

Email Alerts Receive free email-alerts when new articles cite this article. Sign up at:

http://ijssurgery.com/alerts

The International Journal of Shing Surgerih 2397 Waterbury Circle, Suite 1,

Aurora, IL 60504, Phone: +1-630-375-1432 


\section{Remote Cerebellar Hemorrhage Complicating Unintended Durotomy in Lumbar Spine Surgery}

Yizhar Floman, MD, Michael A Millgram, MD, Ely Ashkenazi, MD, Nahshon Rand, MD

Israel Spine Center at Assuta Hospital, Tel Aviv, Israel

\section{Abstract}

\section{Study design}

Case reports and retrospective review of accidental durotomies in lumbar surgeries during 5 years.

Objectives

To draw attention to a potentially serious complication of incidental durotomy-remote cerebellar hemorrhage.

Summary and background data

Accidental durotomy is a frequent complication of spinal surgery. In most cases the outcome of incidental durotomy is favorable. A delayed potentially serious complication of CSF loss during and after lumbar surgery is remote cerebellar hemorrhage $(\mathrm{RCH})$.

Methods

During 2008-2012, 1169 lumbar spine procedures were performed at our spine center. In 210 surgeries incidental or intentional durotomies occurred. All patients with durotomies were managed with suturing of the dural wound followed by deep wound drainage left for 5 days and tight wound closure.

Results

Of the 210 patients with CSF loss three patients were identified to suffer from $\mathrm{RCH}$-an incidence of $0.26 \%$. The three patients ages 56, 67 and 75 years developed RCH between 36-192 hours after surgery. All three were managed with supportive treatment and close clinical supervision. A gradual clinical and radiological improvement was noted in all three patients.

\section{Conclusions}

Severe headache after spinal surgery and or declining mental status should not be attributed only to low CSF pressure secondary to dural tearing. It can also be the result of remote cerebral or cerebellar hemorrhage. Once the diagnosis of RCH is made, close clinical supervision is mandatory. In most cases non-operative supportive treatment may lead to eventual full clinical recovery.

KEYWORDS: INCIDENTAL DUROTOMY, LUMBAR SURGERY, CSF LOSS, CEREBELLAR HEMORRHAGE

VOLUME 9 ARTICLE 29 DOI: 10.14444/2029

\section{Introduction}

Accidental dural injury is a common complication of spinal surgery. The overall incidence of unintended durotomy is between $1.6 \%$ to $10 \%$ and even more. ${ }^{1,2}$ In most cases the outcome of incidental durotomy is favorable. The most frequent and immediate adverse event of dural tearing and cerebrospinal fluid (CSF) loss is postural nuchal and cranial pain. These bothering symptoms of CSF loss most often resolve spontaneously with bed rest and increased fluid intake. A delayed, potentially serious complication of spinal surgery that is associated with significant CSF leakage that may present initially as severe headache, is remote cerebellar hemorrhage ( $\mathrm{RCH})$. Chadduck ${ }^{3}$ in 1981 was the first to report cerebellar hemorrhage that developed after cervical laminectomy with CSF loss. Since then it was reported to occur after surgery at all spinal levels. This complication develops in a remote anatomical site and not at the spinal surgery site. Initially this serious complication related to CSF loss was considered to be rare. More recently with a better ability to clinically recognize cerebellar hemorrhage more attention has been drawn to this remote 
complication of spine surgery. ${ }^{4}$ We would like to report our clinical experience with RCH due to accidental or planned durotomy at our spine center.

\section{Materials $\mathcal{E}$ methods}

During 2008-2012 1169 lumbar spine procedures were performed at our spine center. Of these 899 were lumbar decompressions, accompanied by instrumentation and fusion and 270 were lumbar discectomies, laminectomies or resection of intradural tumors. In 210 lumbar procedures opening of the dura either incidental or planned with CSF loss was encountered. Durotomies were managed with closure of the dural tear followed by deep wound drainage left for 5 days with "water" tight wound closure. After 5 days the drain was removed and in the vast majority of the patients no exterior CSF leakage was observed. Of the 210 patients with perioperative CSF loss three patients were identified to suffer from delayed $\mathrm{RCH}$ i.e. in $0.26 \%$ of all lumbar surgeries.

\section{Case reports}

Case 1: A 75 female patient underwent decompressive laminectomy and fusion between L2-5 for degenerative scoliosis and spondylolisthesis with spinal stenosis. The patient presented with progressive intermittent claudication. The patient had a history of type 2 diabetes mellitus, hypertension and a right hemispheric stroke with residual minimal hemiparesis. During surgery a tear of the dural sac occurred at a region with dense epidural scarring. The dural wound was sutured and a deep wound drain was left without application of negative pressure. On the 8th postoperative day CSF leak through the wound was noted and this was managed with wound over suturing. The next day the patient was found to be drowsy. Arterial hypertension was noted $(220 / 106 \mathrm{mmHg})$. CT of the head demonstrated hemorrhage in the left posterior fossa (Figure 1). She was managed in the surgical intensive care unit and gradually a clinical and radiological improvement was noted in particular the reappearance of the 4 th. ventricle with gradual resorption of the hematoma.

Case 2: A 67 female patient underwent L4-5 decompression and fusion for degenerative spondylolisthe- sis. She was known to have type 2 diabetes mellitus and hypertension. During surgery a $1 \mathrm{~mm}$ dural tear was noted in a region where a calcified ligamentum flavum was adherent to the dural sac. After dural suturing a subfascial drain without negative pressure was left for 5 days. On the 5 th.postoperative day the patient complained on a severe headache with ataxia. A slurred speech was also noted. CT and MRI revealed a bilateral cerebellar hematoma (Figure 2) with occlusion of the 4 th. ventricle. With supportive treatment a gradual clinical and MRI improvement was noted. A full clinical recovery was noted after a month.

Case 3: A 56 male underwent decompression and fusion for degenerative scoliosis and lumbar spinal stenosis from T10-S1. He was known to have type 2 diabetes mellitus and hypertension. A small dural tear was noted $(1 \mathrm{~mm})$ during surgery. The dural wound was sutured and a subfascial drain was inserted without applying negative pressure. Thirty six hours after surgery severe headache with slurred speech were noted. Arterial blood pressure was 235mmHg. Head CT revealed hematoma in the cere-

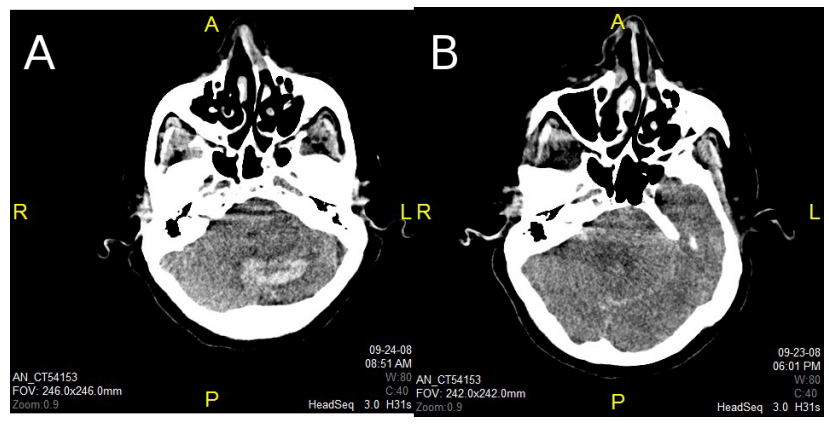

Fig. 1. Case 1. A: CT of the head showing posterior fossa intra-parenchymatous bleeding. B: a different CT cut shows a pattern similar to the Zebra sign.

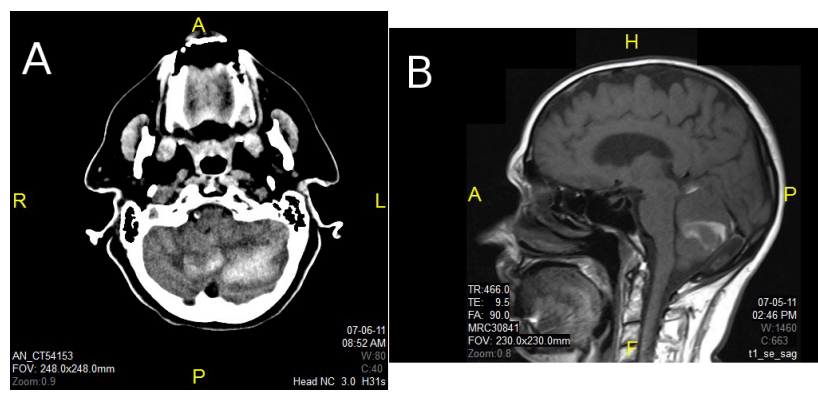

Fig. 2. Case 2. A: CT of the head showing posterior fossa intra-parenchymatous bleeding. B: T1 sagittal image showing the cerebellar hemorrhage 
bellum (Figure 3). A gradual clinical and radiological improvement were noted. In the interim the patient was diagnosed to suffer from acalculus cholecystitis with perforation and underwent a cholecystectomy.

\section{Discussion}

Inadvertent dural tearing and subsequent CSF loss are one of the commonest operative complications during spinal surgery particularly in the lumbar region. Williams et al. studies more than 100000 spinal surgeries and found that the overall incidence of operative dural tears was $1.6 \%{ }^{1}$ The authors found that spinal surgery in elderly patients or revision spinal surgery was associated with a higher incidence of accidental dural tears. Baker et al. ${ }^{2}$ found that surgery in the lumbar spine, surgery for degenerative spine pathologies or surgery in diabetic patients was associated with increased risk for unintended durotomy. Similar findings were reported by Tafazal \& Sell. ${ }^{5}$ Takahashi et al. found that spinal surgery for advanced degenerative facet arthrosis with formation of facet cysts was associated with an even higher incidence- $18 \%$ of unintended durotomies. ${ }^{6}$ Of the 20 cases of $\mathrm{RCH}$ collected by $\mathrm{Choi}^{7}$ six underwent surgery for degenerative spondylolisthesis with facet arthrosis. Two of the 3 currently reported patients had degenerative spondylolisthesis with facet cysts. Therefore a clinical setting prone to accidental durotomy

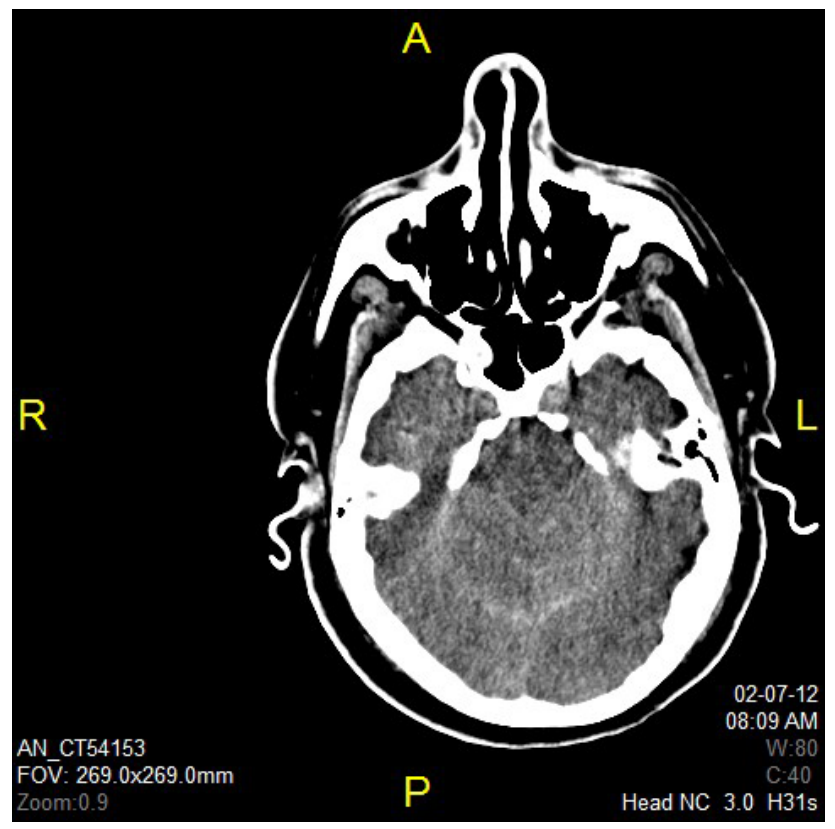

Fig. 3. CT of the head shows the Zebra sign pattern in the posterior fossa. and possible development of $\mathrm{RCH}$ are elderly patient operated for lumbar spinal stenosis with severe facet arthritis possibly with degenerative spondylolisthesis.

In a literature review on spine related $\mathrm{RCH}$ published in $2010 \mathrm{Gul}$ et al. collected 15 reported cases $^{8}$ while Khalatbari et al. ${ }^{9}$ in 2012 were able to collect 30 published cases of RCH after spinal surgery. These figures signify that $\mathrm{RCH}$ is much more common than it is believed to be. Cevik et al. found an incidence of 0.08\% of RCH among more than 2000 lumbar procedures. ${ }^{10}$ In our practice we found a somewhat higher incidence- $0.26 \%$. Khalatbari et al. ${ }^{9}$ reported that 4 out of 1077 lumbar surgeries were complicated by intracranial remote bleeding, 2 patients developed $\mathrm{RCH}$ and 2 additional patients suffered from intracranial bleeding in other sites. It should be noted that a comparable cerebellar bleeding pattern after supratentorial surgery with CSF leak is 3 times more common. ${ }^{8}$ Nevertheless RCH after spinal surgery is more common than anticipated as small cerebellar hemorrhages may occur without producing symptoms. Dincer et al. estimated that the incidence of asymptomatic RCH after supratentorial surgery is $0.8 \% .{ }^{11}$ Since brain imaging is not obtained in the vast majority of cases with CSF loss during spinal surgery, the true incidence of RCH may be underestimated. ${ }^{12,13}$

The clinical picture of $\mathrm{RCH}$ is characterized by intense headache which is the most common symptom, altered level of consciousness, lethargy and drowsiness with slurred speech and other cerebellar symptoms. As noted previously $\mathrm{RCH}$ develops as a delayed complication of spinal surgery. Konya et al..$^{14}$ reviewed the published literature until 2006 and noted that the RCH was diagnosed between 16-120 hours after surgery (47 hours on average). Our experience was similar (36-192 hours).

Although the exact mechanism is unknown it is obvious that RCH is closely linked to excessive CSF leakage as a result of incidental dural tearing during spinal surgery. Even with tight closure of the dural wound excessive CSF leak can occur and potentially result in $\mathrm{RCH} .{ }^{15} \mathrm{It}$ is believed that intracranial hypotension as a result of excessive CSF leakage leads 
to cerebellar sag, stretching of the cerebellar vermian veins with subsequent venous occlusion and hemorrhagic venous infarction. The morphological pattern of $\mathrm{RCH}$ point to the major role of the cerebellar veins in the pathogenesis of this complication. The hemorrhage is located in the upper vermis and cerebellar sulci where the draining veins are situated. The frequent bilateral nature of $\mathrm{RCH}$ also points to venous involvement as arterial involvement is usually unilateral. ${ }^{15} \mathrm{~A}$ support the venous theory of $\mathrm{RCH}$ is the report of chronic cerebellar hemorrhage in spontaneous cranial hypotension associated with ventral spinal CSF leak. ${ }^{16}$

It should be stressed that relative cranial hypotension may occur even without dural tearing. In cases with complete epidural block, for instance in degenerative spondylolisthesis, decompressive laminectomy while acutely relieving the epidural block will result in a temporary cranial hypotension. The addition of a CSF leak may then tip the delicate CSF dynamics and cranial hypotension toward cerebellar sag and venous bleeding.

The classic bleeding pattern of $\mathrm{RCH}$ seen on brain imaging includes blood in the sulci of the cerebellar hemisphers and vermis and frequently intracerebellar hemorrhage in the upper parts of the cerebellum. ${ }^{15}$ Brockmann et al. contended that the so called Zebra sign is typical for RCH. ${ }^{4}$ The Zebra sign is characterized by alternating hyperdense (cerebellar hemorrhage) and hypodense (cerebellar parenchyma) linear bands. Only one of our patients demonstrated the classic pattern of the Zebra sign on cranial imaging.

Contributing factors for the development of $\mathrm{RCH}$ may include occult coagulopathy, anticoagulant therapy or arterial hypertension. ${ }^{17}$ None of our patients had a preoperative coagulopathy but all 3 were managed with Enoxaparin after surgery. In addition all 3 patients suffered from hypertension and diabetes. With the clinical expression of $\mathrm{RCH}$ severe arterial hypertension was noted in two of the three patients reported. This is probably secondary to the intracranial bleeding. Therefore the combination of angiopathy secondary to diabetes with hypertension together with CSF hypotension could lead in concert to the $\mathrm{RCH}$ in our cases.
The prognosis of RCH depends on the extent of bleeding. Although fatal intracranial hemorrhages have been reported to occur after spinal surgery, ${ }^{4}$ the clinical outcome in more than $50 \%$ of the $\mathrm{RCH}$ cases is favorable, most cases will show complete recovery. ${ }^{15}$ All our three cases reported exhibited a full clinical and brain imaging recovery from the posterior fossa bleeding.

In conclusion $\mathrm{RCH}$ after spinal surgery with CSF leak is not so rare. Severe headache after spinal surgery declining mental status and or lethargy should not be attributed only to low CSF pressure secondary to dural tearing. It can also be the result of remote cerebral or cerebellar hemorrhage. Once the diagnosis of RCH is made, most cases may be closely monitored with non-operative supportive treatment with eventual full clinical recovery.

\section{References}

1. Williams BJ, Sansur CA, Smith JS et al. Incidence of unintended durotomy in spine surgery based on 108478 cases. Neurosurgery 68:117-124, 2011.

2. Baker GA, Cizik AM, Bransford RJ et al. Risk factors for unintended durotomy during surgery. A multi variance analysis. The Spine J. 12:121-6, 2012. 3. Chadduk WM: Cerebellar hemorrhage complicating cervical laminectomy. Neurosurgery, 9:185-9,1981.

4. Brockmann MA, Nowak G, Reusche E, Russlies M, Petersen D: Zebra sign. Cerebellar bleeding pattern characteristic of cerebrospinal fluid loss. J Neurosurgery 102:1159-62,2005.

5. Tafazal SI, Sell PJ: incidental durotomy in lumbar spine surgery: Incidence and management. Eur. Spine J.14:287-90, 2005.

6. Takahashi Y, Sato T, Hyodo H, Kawamate T, Takahashi E, Miyatake N, Tokunaga M: Incidental durotomy during lumbar spine surgery: Risk factors and anatomic locations: Clinical article J. Neurosurg Spine 18:165-9,2013.

7. Choi BW Lee SM Yoon MG Moon MS: Cerebellar hemorrhage after posterior lumbar decompression and interbody fusion complicated by dural tear-a case report. J. Korean Society of Spine Surg. 
21:183-188, 2014.

8. Gul S, Kalayci M, Acikgoz B: A rare complication of spinal surgery: cerebellar hemorrhage. Turkish Neurosurgery 20:413-17, 2010.

9. Khalatbari MR, Khalatbari I, Moharamzad Y: Intracerebellar hemorrhage following lumbar spine surgery. Eur. Spine J. 21:2091-96,2012.

10. Cevik B, Kirbas I, Cakir B, Akin K: Remote cerebellar hemorrhage after spinal surgery. European J Radiol 70:7-9,2009.

11. Dincer A, Ozcan U, Kaya D, Usseli M, Erzan C, Pamir MN: Asymptomatic remote cerebellar hemorrhage: CT and MRI findings. Cerebellum 11:880-886, 2012.

12. Freidman JA, Ecker RD, Piepgras DG, Duke DA: Cerebellar hemorrhage after spinal surgery: report of two cases and literature review. Neurosurgery 50:1361-1364, 2002.

13. Hempelmann RG Mater E: Remote cranial parenchimatous hematomas as a complication of spinal surgery: presentation of three cases with minor or untypical symptoms. Eur. Spine J. 21:(suppl 4) 564-68,2012.

14. Konya D, Ozgen S, Pamir MN: Cerebellar hemorrhage after spinal surgery: case report and review of the literature. Eur. Spine J. 15:95-99,2006.
15. Brockmann MA Groden C: Remote cerebellar hemorrhage: A review. The Cerebellum 5:64-8,2006. 16. Schievink W, Maya M, Nudo M:Chronic cerebellar hemorrhage in spontaneous intracranial hypotension: association with ventral spinal cerebrospinal fluid leaks. J Neurosurg Spine 15:433-40,2011.

17. Thomas G, Jayaram H, Cudlip S, Powel M: Spontaneous and infratentorial intraparenchymal hemorrhage secondary to intracranial CSF hypotension following spinal surgery. Spine 27:E410-E412, 2002.

\section{Disclosures}

The authors declare no relevant financial interests.

\section{Corresponding Author}

Yizhar Floman, Israel Spine Center, Habarzel 20, Tel Aviv 69710 Israel. yizhar1@012.net.il

Published 14 July 2015.

This manuscript is generously published free of charge by ISASS, the International Society for the Advancement of Spine Surgery. Copyright ๑ 2015 ISASS. To see more or order reprints or permissions, see http://ijssurgery.com. 